\title{
Preparation and Properties of Supercapacitor with Composite Electrodes
}

\author{
Chih-Ming Wang ${ }^{\mathrm{a},{ }^{*}}$, Chih-Yu Wen ${ }^{\mathrm{b}}$, Ying-Chung Chen ${ }^{\mathrm{b}}$, Jui-Yang Chang ${ }^{\mathrm{b}}$, Jian-Zhen Huang $^{\mathrm{b}}$ and Chien-Chung Hsu ${ }^{\mathrm{b}}$ \\ ${ }^{a}$ Department of Electrical Engineering, Cheng Shiu University, Kaohsiung 833, Taiwan \\ ${ }^{\mathrm{b}}$ Department of Electrical Engineering, National Sun Yat-Sen University, Kaohsiung 804, Taiwan
}

*Corresponding Author: cmwang @gcloud.csu.edu.tw

\begin{abstract}
In this study, composite actived carbon of $\mathrm{NiO}$ coated mesocarbon microbeads with a high-specific surface area $\left(2685 \mathrm{~m}^{2} / \mathrm{g}\right)$ were formed by the chemical method. In this experiment, the composite actived carbon was prepared by filtering the composite solution and heat treatment. For finding the optimal processing parameters of composite electrode, the temperature of heat treatment, the amount of carbon black on the capacitative properties of supercapacitor were investigated. The structural characteristics of composite actived carbon and electrodes were observed by using XRD, SEM and EDS composition analysis. The capacitive performance of composite electrodes was evaluated by the cyclic voltammograms

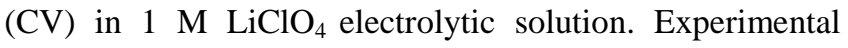
results reveal that the optimum composite electrode was prepared for the molarity $1 \mathrm{M} \mathrm{NiO}$ and temperature of heat treatment $250^{\circ} \mathrm{C}$ and adding 25 wt.\% carbon black and the specific capacitances of composite electrodes is $210 \mathrm{~F} / \mathrm{g}$.
\end{abstract}

Keywords: Mesocarbon microbeads, Nickel oxide, Supercapacitor, Composite electrode, Specific capacitance.

\section{Introduction}

A supercapacitor is a new storage device positioned between traditional capacitors and batteries, which use electrochemical activated materials or porous materials for storage. The advantages of supercapacitors are high power density, high energy density, good cycle life, and fast charge/discharge times ${ }^{(1-2)}$. Therefore, supercapacitors could improve the disadvantages of the traditional batteries and capacitors, and they have attracted considerable attention in recent years.

Helmoholtz (1879) discovered that charge can be separated by coulomb electrostatic force and form double layers across the surface of the electrode and the electrolyte $^{(3)}$. The concept of an electrical double-layer capacitor (EDLC) is applying DC voltage to electrodes that are typically porous carbon. Becker et al. first introduced activated carbon (AC) as the electrode material of EDLC in $1957^{(4)}$. In 2000, Salitra et al. used different electrolytes including $\mathrm{LiCl}, \mathrm{NaCl}, \mathrm{KCl}, \mathrm{LiBF}_{4}$ and $\mathrm{Et}_{4} \mathrm{NBF}_{4}$ to investigate the capacitive performances of the actived carbon of different pore structures ${ }^{(5)}$. Experimental results reveal that the actived carbon of different pore structures need to use the appropriate electrolytes.

In recent years, to improve capacitive performance, many studies have used composite materials to fabricate composite electrodes for use in supercapacitor applications. In this study, activated carbon with a highly-specific surface area was combined with transition metal oxide to fabricate composite electrodes. The composite electrodes exhibited advantages of double-layer capacitance and pseudo-capacitance. Composite electrodes also increased the charge adsorption and electric conductivity by activated carbon and upgrading the specific capacitances of transition metal oxide through a redox reaction. Composite electrodes increase both the power and energy densities of composite materials. In literatures, Beliakov et al. first introduced composite materials as composite electrodes in $1997^{(6)}$. $\mathrm{Li}$ et al. synthesized composite electrodes by using $\mathrm{RuO}_{2} \cdot \mathrm{H}_{2} \mathrm{O}$ and porous carbon, and investigated the characteristics of the capacitor regarding annealing temperature ${ }^{(7)}$.

In this study, composite activated carbon was formed by using a chemical method. The influence of heating temperature and the amount of carbon black on the properties of a supercapacitor were investigated to determine the optimal processing parameters of composite electrodes.

\section{Experimental}




\subsection{Preparation of composite actived carbon}

First, a solution of composite activated carbon was produced by uniformly mixing $1 \mathrm{M}$ of $\mathrm{NiO}$ solution and mesocarbon microbeads. Subsequently, the composite solution was filtered by using filter paper with a $150-\mathrm{nm}$ pore size and a composite slurry was obtained to execute the heat treatment in a Thermolyne-1400 Furnace at 200, 250,300 , and $400^{\circ} \mathrm{C}$ in air for $1 \mathrm{~h}$. Finally, the core-shell structure composite activated carbon (MCMB@NiO) was obtained.

\subsection{Fabrication of composite electrodes}

The composite electrodes in this study were fabricated by treating composite activated carbon four different temperatures of heat treatment. Carbon black was added to improve electrode conductivity. The carbon black content was between 0 and 50 wt.\%. After the composite carbon and carbon black powder were uniformly mixed, they were added to a solution of polyvinyl butyral (PVB) in dimethylacetamide (DMA), and the PVB content was 2 wt.\%. The mixture was mixed at room temperature to form a composite carbon slurry. The composite electrodes were prepared by spin-coating the composite carbon slurry onto the ITO glass and then evaporating the DMA solvent in an oven at $150^{\circ} \mathrm{C}$ in air for $15 \mathrm{~min}$.

In this study, a physical adsorption analyzer was used to explore the BET surface area and the pore structure of AC. The surface morphology of the carbon electrode was analyzed using a field emission scanning microscope (FE-SEM). Cyclic voltammetry measurements of the carbon electrodes were performed using an electrochemical analyzer (CH Instruments, 6273E) in two-electrode cells.

\subsection{The analysises of $\mathrm{MCMB} @ \mathrm{NiO}$ and electrodes}

In the physical analyses conducted for this study, we used a field emission scanning microscope (FE-SEM), X-ray diffraction (XRD) and an energy dispersive spectrometer (EDS) to examine the composite carbon and electrodes. In electrical analysis, we used cyclic voltammetry measurements ( $\mathrm{CH}$ Instruments, 6273E) in two-electrode cells to investigate the effects of the temperature of the heat treatment and the amount of carbon black on the capacitate properties of the supercapacitor.

In the $\mathrm{CV}$ curve analysis, a scan rate of $25 \mathrm{mV} / \mathrm{s}$ was used to measure the voltage current change in $1 \mathrm{M}$ of $\mathrm{LiClO}_{4}$ electrolyte with a voltage range of $-3 \mathrm{~V}$ to $3 \mathrm{~V}$. The following equation was used to calculate specific capacitance:

$$
C_{S}=\frac{d Q}{d V}=\frac{1}{m v \Delta V} \int_{V_{1}}^{V_{2}} I(V) d V
$$

where $\int_{V_{1}}^{V_{2}} I(V) d V$ is the hysteresis loop area, $v$ is scan rate, $\Delta V$ is the range of potential, $m$ is the whole weight of the electrode material.

\section{Results and discussion}

Figure 1 shows the X-ray differation plot of the composite activated carbon which formed by using heat treatment at different temperatures. The intensities of the $\mathrm{NiO}$ peaks (111), (200), and (220) clearly increased as heating temperature was increased. The peaks of $\mathrm{NiO}$ were observed by using JCPDS card 47-1049 ${ }^{(8)}$.

Figures 2 (a) (e) presents SEM micrographs of the composite activated carbon surfaces heated at different temperatures. When the temperature increased, the $\mathrm{NiO}$ crystal structures became more obvious and the MCMB@NiO core-shell structure of $\mathrm{NiO}$ coated at mesocarbon microbeads became complete.

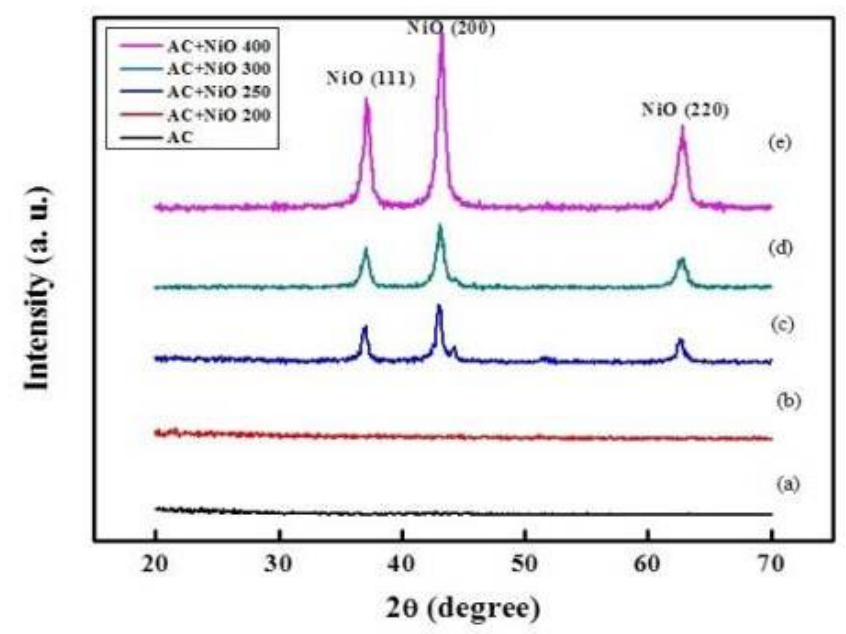

Fig 1. The XRD patterns of the composite actived carbon heated at (a) $\mathrm{AC}$, (b) $200^{\circ} \mathrm{C}$, (c) $250^{\circ} \mathrm{C}$, (d) $300^{\circ} \mathrm{C}$, (e) $400^{\circ} \mathrm{C}$.

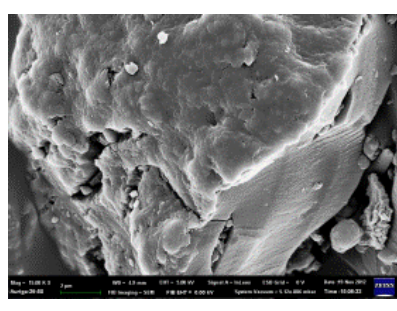

(a)

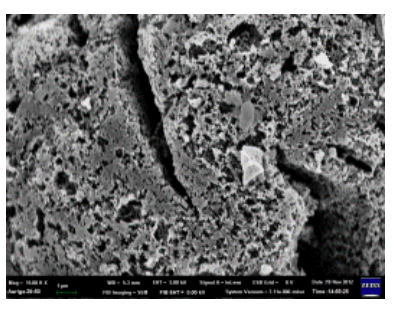

(b) 


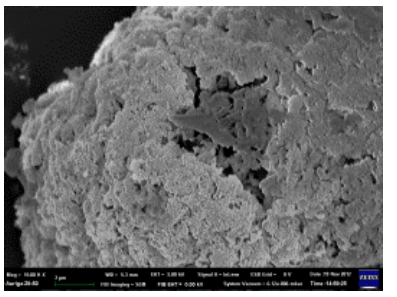

(c)

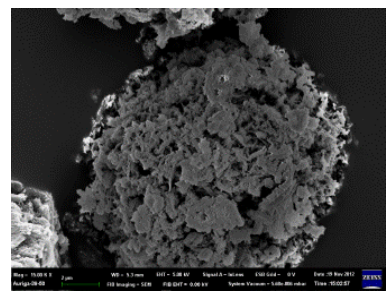

(d)

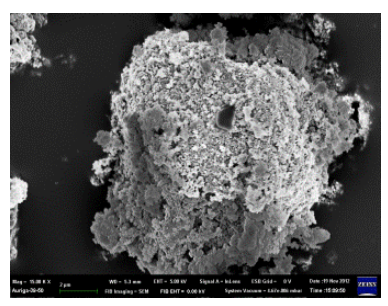

(e)

Fig 2. SEM micrographs of the composite actived carbon surfaces heated at (a) $\mathrm{MCMB}$, (b) $200^{\circ} \mathrm{C}$, (c) $250^{\circ} \mathrm{C}$, (d) $300^{\circ} \mathrm{C}$, (e) $400^{\circ} \mathrm{C}$.

Based on the preparation of MCMB@ $\mathrm{NiO}$ electrodes, composite powders with the heat treatment of different temperatures were used for finishing the electrodes. In this experiment, 30 wt.\% CB was added to the MCMB@NiO carbon slurry to improve electrode conductivity. During a follow-up experiment, the effect of adding various CB contents on capacitance was examined and is discussed in detail. After the composite electrodes were finished, the capacitive characteristic was analysed by using $\mathrm{CV}$ in $1 \mathrm{M}$ of $\mathrm{LiClO}_{4}$ with a voltage range of $-3 \mathrm{~V}$ to $3 \mathrm{~V}$ and a scan rate of $25 \mathrm{mV} / \mathrm{s}$. Figures 3 shows the $\mathrm{CV}$ results from the composite activated carbon according to different heating temperatures.

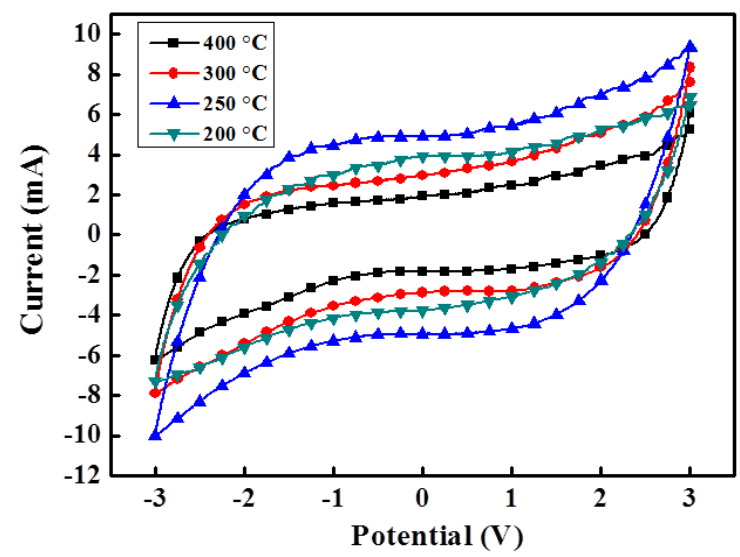

Fig 3. Cyclic voltammograms of MCMB@NiO electrodes using composite activated carbon with different heating temperature.

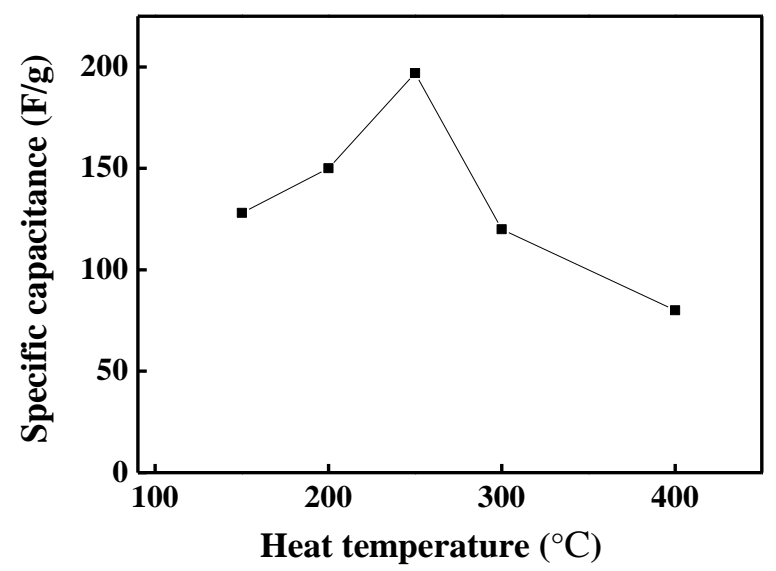

Fig 4. Specific capacitances with different heating temperatures.

In the heating temperatures of $250^{\circ} \mathrm{C}$, the hysteresis loop area is obviously the largest and its specific capacitance, which was calculated using Eq. (1), was 193 F/g. Figures 4 show all the specific capacitances which were calculated at different heating temperatures.

Adding conductive carbon black in the MCMB@NiO electrodes can promote the capacitive characteristic. Figures 5 (a) (g) presents SEM micrographs of the MCMB@NiO electrode surfaces, showing that the surface of the composite powders were covered with tiny $\mathrm{CB}$ powder. When the $\mathrm{CB}$ content was greater than $25 \mathrm{wt} . \%$, the surfaces of electrode were almost covered with $\mathrm{CB}$ and caused the mass of the electrode to increase.

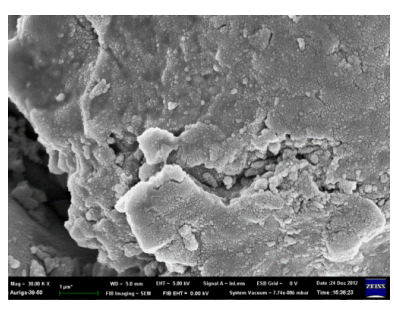

(a)

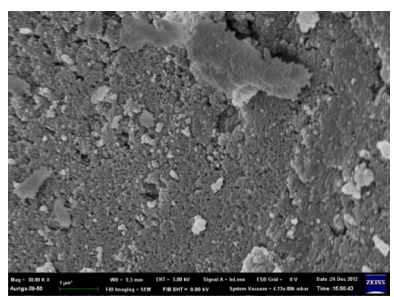

(c)

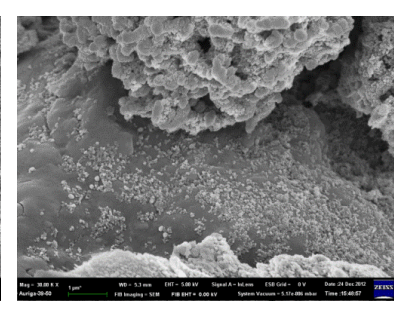

(b)

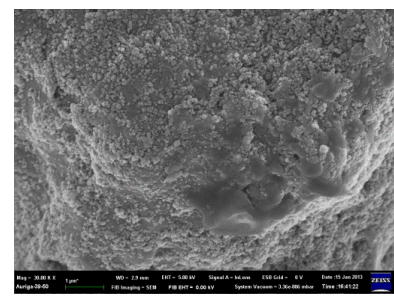

(d) 


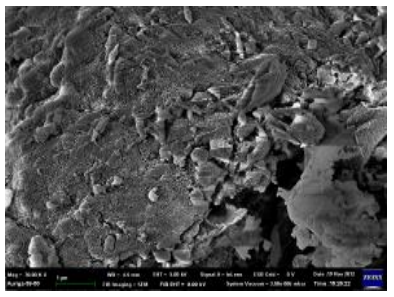

(e)

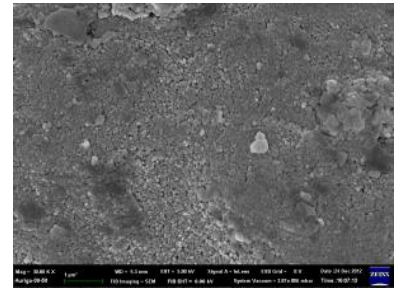

(f)

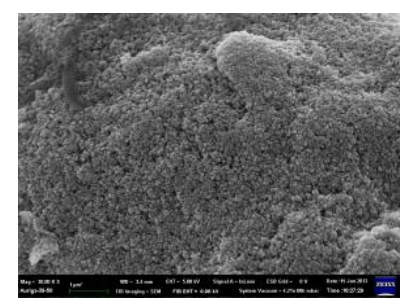

(g)

Fig 5. SEM morphology of MCMB@NiO electrodes with different amount of carbon black: (a) $0 \mathrm{wt} \%$,(b) $10 \mathrm{wt} \%$, (c) $20 \mathrm{wt} . \%$, (d) $25 \mathrm{wt} . \%$, (e) $30 \mathrm{wt} . \%$, (f) $40 \mathrm{wt} . \%,(\mathrm{~g})$ 50 wt. $\%$.

Figures 6 shows the CV results of adding various CB contents. The hysteresis area obviously increased when the CB content increased. However, the mass of electrodes increased rapidly when the content was greater than 25 wt.\%. According to Eq. (1), the specific capacitance was $210 \mathrm{~F} / \mathrm{g}$.

Table 1 shows the EDS analysis of MCMB@NiO electrodes. The proportion of nickel was investigated by adding conductive CB powder. When 0 wt.\%, 25 wt.\% and 50 wt. $\%, \mathrm{CB}$ was added, the nickel proportion decreased and the carbon proportion increased gradually. The results indicate that the nickel proportion is reduced when $\mathrm{CB}$ is added. According to the literature ${ }^{(8)}$, the characteristics of capacitance could be improved by adding conductive CB powder to electrodes. Therefore, the composite electrodes that had 25 wt.\% conductive CB powders exhibited the maximum specific capacitance and energy density ${ }^{(10)}$.

Table 1. EDS analysis of composite electrodes.

\begin{tabular}{|c|c|c|c|c|}
\hline & $\begin{array}{c}\text { Carbon } \\
\text { element } \\
\text { proportion } \\
(\%)\end{array}$ & $\begin{array}{c}\text { Nickel } \\
\text { element } \\
\text { proportion } \\
(\%)\end{array}$ & $\begin{array}{c}\text { Specific } \\
\text { Capacitance } \\
\text { (F/g) }\end{array}$ & $\begin{array}{l}\text { Energy } \\
\text { density } \\
\text { (Wh/kg) }\end{array}$ \\
\hline Owt. $\%$ & 72.26 & 3.77 & 52 & 65 \\
\hline 25 wt. $\%$ & 76.40 & 2.19 & 210 & 262 \\
\hline 50 wt. $\%$ & 81.85 & 1.51 & 50 & 62 \\
\hline
\end{tabular}

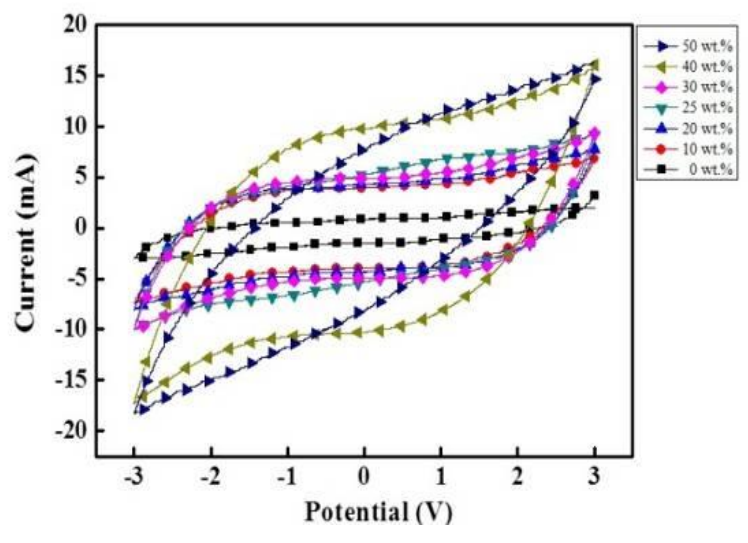

Fig 6. Cyclic voltammograms of MCMB @NiO electrodes with different content of carbon black.

\section{Conclusions}

This study focused on composite activated carbon and composite electrodes. Composite activated carbon was formed by using a chemical method. When the heating temperature increased, the $\mathrm{NiO}$ crystal structures became more obvious and the composite core-shell structure of $\mathrm{NiO}$ coated mesocarbon microbeads became complete. In the heating temperature of $250^{\circ} \mathrm{C}$, the hysteresis loop area was obviously the largest and its specific capacitance was 193 F/g. Regarding composite electrodes, when carbon black was increased, the specific capacitance decreased. In conclusion, the optimal parameters of composite electrodes were obtained by using $1 \mathrm{M}$ of $\mathrm{NiO}$, a heat temperature of $250^{\circ} \mathrm{C}$, the addition of $25 \mathrm{wt} \%$ carbon black, and the specific capacitance is $210 \mathrm{~F} / \mathrm{g}$.

\section{Acknowledgment}

This study was supported by the Ministry of Science and Technology of the Republic of China, Taiwan, under contract number MOST 104-2221-E-230-008.

\section{References}

(1) M. K. Teng : "Study the electrode materials of electrochemical capacitor", USTC, China, 2009

(2) D. H. Fritts : "An Analysis of Electrochemical Capacitors", J. Electrochem. Soc., Vol. 144, Issue 6, 2233-2241, 1997

(3) Von Helmholtz, H. L. F. : "Studies of electric boundary layers.", Wied. Ann, Vol. 7, 337-382, 1879

(4) H. L. Becker, : "Low voltage electrolytic capacitor", 
US Patent, 2800616, 1957

(5) G. Salitra, A. Soffer, L. Eliad, Y. Cohen and D. Aurbach : "Carbon Electrodes for Double-Layer Capacitors I. Relations Between Ion and Pore Dimensions", J. Electrochem. Soc., Vol. 147, Issue 7, 2486-2493, 2000

(6) A. I. Beliakov and A. M. Brintsev : in Proceedings of the 7th International Seminar on Double Layer Capacitors and Similar Energy Storage Devices, Florida Educational Seminars, December 8-10, 1997

(7) H. F. Li, R. D. Wang, R. Cao : "Physical and electrochemical characterization of hydrous ruthenium oxide/ordered mesoporous carbon composites as supercapacitor", Microporous and Mesoporous Materials, Vol. 111, 32-38, 2008

(8) J. Cheng, G. P. Cao, Y. S. Yang : "Characterization of Sol-Gel-Derived NiOx Xerogels Supercapacitors", J. Power Sources, Vol. 159, No. 1, 734-731, 2006

(9) N. L. Wu and S. Y. Wang : "Conductivity percolation in carbon-carbon supercapacitor electrode", J. Power Sources, Vol. 110, 233-236, 2005

(10) J. P. Zheng and T. R. Jow : "High energy and high power density electrochemical capacitors", J. Power Sources, Vol. 62, 155-159, 1996 